OPEN ACCESS

Edited by:

Michael S. Dempsey, Boston University, United States

Reviewed by:

Pradeep Nair

Central University of Himachal

Pradesh, India

Pei Sun,

Tsinghua University, China

*Correspondence:

Jari Metsämuuronen

jari.metsamuuronen@nla.no;

jari.metsamuuronen@gmail.com

Specialty section:

This article was submitted to

Educational Psychology,

a section of the journal

Frontiers in Psychology

Received: 15 January 2018 Accepted: 28 November 2018

Published: 12 December 2018

Citation:

Metsämuuronen $J$ and Räsänen $P$ (2018) Cognitive-Linguistic and Constructivist Mnemonic Triggers in Teaching Based on Jerome

Bruner's Thinking.

Front. Psychol. 9:2543.

doi: 10.3389/fpsyg.2018.02543

\section{Cognitive-Linguistic and Constructivist Mnemonic Triggers in Teaching Based on Jerome Bruner's Thinking}

\author{
Jari Metsämuuronen ${ }^{1 *}$ and Pekka Räsänen² \\ ${ }^{1}$ Department of Pedagogy, NLA University College, Bergen, Norway, ${ }^{2}$ Niilo Mäki Institute, Jyväskylä, Finland
}

Effective teachers use mnemonic tools or mnemonic triggers to improve the students' retention of the study material. This article discusses mnemonic triggers from a theoretical viewpoint based on Jerome S. Bruner's writings. Fifty small linguisticcognitive, constructive-, rhetorical-, and phonological-mnemonic triggers are detected. These triggers may become supporting elements for our memory system when we are "constructing the realities" in a Brunerian sense when we are ordering, differentiating, comparing, and handling information, stories and experiences in our mind. Many of these are small, hidden linguistic elements in speech. This article discusses their usage in the educational talk and textbooks.

Keywords: Jerome Bruner, constructivist learning theories, cognitive psychology, educational psychology, mnemonics, mnemonic triggers, teaching

\section{HOW TO TEACH THE MATERIAL SO THAT IT COULD BE REMEMBERED THE MOST EFFECTIVE WAY?}

Let us visualize a simple test of listening to a list of 31 words ordered in an alphabetical order and trying to remember those by heart:

A, And, Are, Ask, Because, Carefully, Concepts, Examination, Final, I, Important, In, Listen, Now, Of, Of,

Psychometrical, Referring, Reliability, Terms, Test, The, The, The, These, To, Trustworthiness, Ultimately,

Validity, When, Will

Some other rationale such as the length of the words could be used also in ordering the list. Even if the test-takers would not be familiar with concepts in the list, it is obvious that, after listening to the material repeatedly, they would learn the words by heart without a problem within a couple of tens of minutes-maybe even in $10 \mathrm{~min}$. Some of the test-takers would need somewhat more time with the task than some others would do but, anyhow, all could solve the task [see the classical experiments of learning and memorizing the lists of foreign words by Tulving (1967) and Roediger and Karpicke, 2006a,b; Karpicke and Roediger, 2008]. That is not a problem.

The task would be much easier and faster if we organized the list of words in the following sequence:

Now, listen carefully because I will ask these concepts in the final examination. The terms of reliability and validity are ultimately important when referring to the trustworthiness of a psychometrical test. 
We may ask why we would remember the words better, faster, and prolonged way when the data was given in the latter order instead of the former order. O'Keefe and Nadel (1998), pp. 388389) propose when the information is categorized either in the verbal or visual form, it reduces the amount of information that needs to be retrieved. They assume a kind of semantic map in the brain (specifically in hippocampus) (ibid. p. 410). This article discusses the matter from mnemonic triggers viewpoint and proposes a hypothesis related to the example above: we use hidden or obvious linguistic-cognitive, constructive-, rhetorical-, and phonological mnemonic triggers to guide the attention, and to enhance the encoding, and recall of the material to be learnt. The questions discussed in this article are what those triggers are and how to detect those. The focus is on classifying the triggers based on the relevant research literature, and to form a theoretical framework for the further studies and practical use.

From the educational psychology viewpoint, this brings us to an essential practical question: what kind of teaching talk or study material is effective and why? In this article, the effectiveness is narrowed down to retention and retrieval-such teaching or educational material is effective which leaves a measurable change in the memory or in the behavior of a student. This measurable change, or "a memory" may be detected physically from the brain $^{1}$ and can be recalled or observed as a change in the behavior of the learner. Here, the concept of "teacher" and "teaching" is enlarged to cover not only the instructor as a human being, but also the consciously organized teaching material such as books, articles, or lecture notes meant to be read and learnt without the human instructor as well as, in the near future, virtual teachers run by artificial intelligence. The writer of a textbook or an article in a compendium for students is a teacher though not necessarily physically present. This brings us close to the idea of two types of teaching discussed by Biesta (2013, 2016): "learning from" and "being taught by" a teacher. The first means that a teacher is a resource for the student and the latter implies a "teaching" teacher. Both are relevant aspects of being a teacher.

An effective teacher uses such methods deliberately that are aimed to improve the retention and recall of the study material. We call these methods mnemonic tools (e.g., Bafile, 2005), mnemonic devices (e.g., Sökmen, 1997; Haydon et al., 2017, pp. 240-241), mnemonic strategies (e.g.,

\footnotetext{
${ }^{1}$ The results of O'Keefe (1976), O'Keefe and Dostrovsky (1971) and the studies of Moser group in Norway from 2004 on (see Rowland et al., 2016) are worth mentioning here. "They have opened new avenues for understanding other cognitive processes, such as memory, thinking and planning" as the Nobel assembly puts it in 2014 (https://www.nobelprize.org/nobel_prizes/medicine/laureates/2014/press.html).

O'Keefe and May-Britt Moser and Edvard I. Moser were jointly awarded the 2014 Nobel Prize for their discoveries of cells that constitute a positioning system in the brain. This means that, for the first time, we were able to detect and locate the higher-level thinking processes at a neural level. It is still a long way before we may locate higher cognitive operations such as analyzing, synthesizing, or evaluating (see the Bloom's taxonomy for cognitive domain in Bloom, 1956). Our understanding how the brain is actually making and recalling the memory is very limited (Epstein, 2016) —-we tend to use metaphors such as "computing" or "information processing" or "memory" which all seem to be just vague images of what actually happens in the brains.
}

Mastropieri et al., 1992; Mastropieri and Scruggs, 1998), mnemonic instructions (e.g., Mastropieri and Scruggs, 1989, 1991; Lubin and Polloway, 2016), or mnemonic triggers (e.g., Metsämuuronen, 2010). ${ }^{2}$ These mnemonic triggers are the subject of this article. Mnemonics and mnemonic instructions have been studied widely specifically within the special education (see literature in Mastropieri and Scruggs, 1998; Lubin and Polloway, 2016). This literature is not reviewed here as the focus is on Bruner's ideas and possible new mnemonic triggers found in his writings. However, as a reasonable outcome of the literature, Mastropieri and Scruggs (1998), p. 1) note: "We recommend mnemonic strategies for only one reason: Over and over again, they have been proven to be extremely effective in helping people remember things."

Some elementary concepts and theories of constructive psychology are discussed in Section "Constructivism and Cognitive Psychology in the Contemporary Educational Discourse" and of cognitive psychology in Section "Memory and Cognitive Models." Brunner's legacy in the educational psychology and his ideas and the basic mnemonic triggers are discussed in Section "Bruner and Mnemonic Triggers."

\section{CONSTRUCTIVISM AND COGNITIVE PSYCHOLOGY IN THE CONTEMPORARY EDUCATIONAL DISCOURSE}

Regardless some few critical voices ${ }^{3}$, constructivist learning theories and constructivism have superseded, more or less, the naturalistic approaches, such as the behaviorist and cognitivists learning theories, in the contemporary educational practices, discourse, and language. There are several reasons for this. One is that constructivism justifies students' being active learners instead of passive receivers. Another is that the development of higher-level thinking, including the complex use of language, is very difficult to explain from the behaviorist and cognitivist approaches. We can easily find several more reasons. Despite the possible challenges ${ }^{4}$ in the epistemological base of the constructivism (see Puolimatka, 1999, 2003; Nodding, 2016, p. 122), the practical educators have found constructivist learning theories helpful in their work and many researchers from deviating aspects have used these as relevant background theories for their studies. Some of the recent publications with constructivist learning theories as the theoretical framework have tackled the use of technology (Alabdulaziz and Higgins, 2017;

\footnotetext{
${ }^{2}$ The term "mnemonic" (from Greek mnçmoneuein, "to remember") tool refers to all conscious and unconscious techniques and methods a speaker or a teacher uses to enhance the retention and recall of the message in the audience. It should not be confused with "mnemonics" which are used by the listener or student as methods for remembering the information that is otherwise difficult to recall (see Bafile, 2005). Baddeley (1997, pp. 133-134) does not make the difference but the distinction serves the idea of the article.

${ }^{3}$ e.g., Phillips (1995, 1997, 1999), Puolimatka (1999, 2002, 2003), and Nodding (2016).

${ }^{4}$ According to Puolimatka (2003), for example, a challenge in constructivism is that the constructivist view of knowledge does not provide us an adequate epistemological framework for the critical thinking.
} 
Harasim, 2017), business ethics (Lämsä et al., 2017), professional development (Shore and Morris, 2016), curriculum studies (van Bommel et al., 2015), higher education (Bhola and Parchoma, 2015), augmented reality teaching (Dunleavy and Dede, 2014), experiential learning (Kolb, 2014), and linguistics (Jiang and Perkins, 2013)-just to mention a few. Though there are different theories and practical solutions in constructivism in the educational realm these share the general humanistic basic tenet that "people construct their own understanding and knowledge of the world through experiencing the world, and reflecting on those experiences," as expressed by Harasim (2017, p. 62). Duffy and Cunningham (1996, p. 177) put it as "learning is an active process of constructing rather than acquiring knowledge." Both of these originate from Bruner (1961).

Constructivist learning theories are one branch of the movement of cognitive sciences strongly affected by Jerome $S$. Bruner's works from the 1950s on (see Bruner and Goodnow, 1986). While the constructivist learning theories rose from the humanistic tradition (from Piaget and Bruner) and social cultural tradition (from Vykotsky, 1925), in the same wave of cognitive sciences, the cognitive psychology developed from Miller (1956) and Broadbent (1958) from the tradition of natural sciences, and cognitive linguistics from Chomsky (1957) from the tradition of linguistics. All these traditions have tried to explain the "mind," or mental processes, in a human-constructivists from the humanistic viewpoint, cognitive linguistics from the semantics viewpoint, and psycholinguistics or cognitive psychologists from the neural viewpoint. They all share the basic tenet that at least part of the human linguistic ability is innate, and that language is embedded in the overall cognitive capacities of man (Geeraerts, 1995, p. 111; Taylor, 1984, p. 223). Also, the basic theories (or at least their foundations) of the storage and retrieval, or memory and retention, of linguistic data are largely shared. Though having been criticized by constructive psychologists (e.g., Bruner, 1985, p. 31), cultural psychologists (e.g., Schweder, 1991, p. 73), educational psychologists (e.g., Säljö,, 2000, p. 56), and philosophers (e.g., Taylor, 1985) cognitive neuroscience has opened promising doors to understanding how the human mind actually works at the neural level. Taylor (1984, p. 223) reminds us that also the constructivists (should) think that there has to be a common biogenetical and personal developmental ground in our minds-otherwise it would be impossible to communicate with each other. According to Taylor (1984, p. 212), in Bruner's thinking, the language skill, that is, our thinking, is based on biological factors but this biological capacity requires cultural expression. Bruner's thinking seems to be a kind of link among the humanistic constructivism, naturalistic cognitive neurosciences, and cognitive linguistic.

Bruner's role in the development of the modern educational thinking is important. This article combines his essential ideas of cognitive processes related to learning and tries to find a practical theory for the empirical works of the essential cognitivelinguistic and constructive triggers that are elementary for constructing the "possible worlds" (Bruner, 1986). This article is mainly theoretical, and the triggers are discussed in the light of Bruner's writings.

\section{MEMORY AND COGNITIVE MODELS}

According to the widely accepted Atkinson and Shiffrin (1968) model, the key processes of learning and memory are multistaged. When new information is taken in, it is in some ways manipulated before it is stored. This stage theory describes three types of memory: sensory memory, working memory, and longterm memory. The short-term or working memory refers to our capacity to hold a small amount of information in an active state while doing a task (originally proposed by Miller, 1956; see also Baddeley, 1997, 2003; Miyake and Shah, 1999). The contents of the long-term storage and retrieval from it are strongly dependent how information is processed at the earlier stages.

The basic theories of human mind claim that the human long-term memory can be divided into two main categories: declarative memory and procedural (or non-declarative) memory (e.g., Squire, 2009; Eysenck and Keane, 2010). Declarative memory concerns things that can be brought to mind and declared, that is, facts that can be explicitly stated. Procedural memory, on the other hand, stores the motor and cognitive skills and habits and its contents cannot be put into words (Poldrack and Packard, 2003; Ullman, 2004; Squire, 2009). Declarative memory can be further divided into semantic and episodic (or narrative) memory (e.g., Tulving, 1983; Bruner, 1986, 1990a). Episodic memory consists of a store of the memories of personal events and actions. The units of episodic memory are events and episodes. Schacter et al. (2007) describe an additional role for the episodic memory system. Episodic memory is by large constructive, and therefore it allows us not only to think about the past experiences, but also to build mental simulations of the imagined future. In this sense, episodic memory may serve in a large role, e.g., in decision-making, creativity and problemsolving (Madore et al., 2017).

Semantic memory is connected to the knowledge concerning the world-it is independent of the identity of the person and of personal history (Tulving, 1983, p. 9). The units of semantic memory are facts and concepts. The content of semantic memory is something the individual knows whereas the content of episodic memory is something the individual remembers. The semantic memory is organized in concepts and episodic memory is organized in time.

Memory depends on attention; attention and memory cannot operate without each other (Chun and Turk-Browne, 2007). Attention and its connection to brain activities and memory is widely studied (see, practical studies, for example, by Simola et al., 2014; Moisala, 2017; Salo et al., 2017; Rämä et al., 2018), and only some basic ideas are raised here to connect the mnemonic triggers to attention. Chun and Turk-Browne (2007) suggest that, first, memory has a limited capacity, and, hence, attention determines what will be encoded and, second, memory from past experiences guides what should be attended. Cowan $(1988,1998)$ have proposed a model how the attention and memory are linked to each other. According to Cowan's model, although relatively unprocessed elements of long-term memory can be automatically activated, new associations between items, and between each item and its context, may be set up only in the focus of attention. Information that is temporarily in or near conscious awareness 
is in the focus of attention. Some attention is probably needed to perceive items adequately. Beyond that, one can distinguish between memory with less versus more attention devoted at the time of encoding.

The memory retrieval is determined by the conditions of acquisition or encoding and the relation between encoding and retrieval operations. The more meaningful the analyses of stimuli at hand are, the higher the levels of subsequent retention will be (Craik and Lockhart, 1972; Craik, 2016). While this levels-ofprocessing effect has been mostly studied in the context of verbal information, in their recent study, Baddeley and Hitch (2017) showed the similar mechanisms can be found in retention of visual information.

Cognitive models assume that the retention and retrieval of memory can be explained by co-operation between working memory and long-term memory. Working memory refers to the temporary retention of information that was just experienced or just retrieved from long-term memory. It is short-lived but can be stored for longer periods of time through active maintenance or rehearsal strategies. Even though multiple factors are connected to better results in memory tasks, declarative memories are best established by using active recall combined with mnemonics and spaced repetition ${ }^{5}$ (Tulving and Schacter, 1990; Baddeley, 1997). The wealth of studies has shown their benefits in designing education and pedagogies to boost long-term retention (see recent reviews, e.g., Toppino and Gerbier, 2014; Larsen, 2018). In the models of Cowan $(1998,2017)$ and Anderson (1983) the working memory is not considered as a separate storage buffer but functions via different levels of activation of the long-term memory storage that is distributed in various areas of the brain. In this way, the memory retrieval plays an important role in the functioning of the working memory. Likewise, these models connect the attention-directing part of the working memory, "the central executive" (Baddeley, 1997) to long-term storage retrieval.

A basic doctrine of human learning and memory research is that repetition of material improves its retention (see Tulving, 1967). This tenet was challenged by Karpicke and Roediger (2008), Roediger and Karpicke (2006a,b) and earlier by Tulving (1967). Their experiments showed that delayed recall is optimized, not with repeated studying sessions, but with repeated testing sessions. Metsämuuronen (2013); also, Metsämuuronen and Mattsson (2013) shows practical results supporting this theoretical result. The result was re-interpreted by Lasry et al. (2008). They hypothesized that repeated testing might lead to multiple traces to the memory, which facilitate recall, and suggested that the new interpretation would lead to a new framework for explaining the effectiveness of frequent in-class assessments in pedagogies such as Peer Instruction. Alternatively, these could be organized by using feedback via cues to guide the task process (Hattie and Timperley, 2007) often with the aid of learning technologies (e.g., Van der Kleij et al., 2015).

\footnotetext{
${ }^{5}$ Spaced repetition is a learning technique that incorporates increasing the intervals of time between subsequent reviews of previously learned material (Baddeley, 1997). This comes close Bruner's idea of spiral curriculum (Bruner, 1960): the previously learned material is taught/studied again after some time with deepened contents.
}

\section{BRUNER AND MNEMONIC TRIGGERS}

\section{Bruner's General Role in the Educational Psychology}

Jerome S. Bruner (1915-2016) is one of the key figures of the modern constructivist theories in education along with the Swiss psychologist Jean Piaget (1896-1980) and Russian psychologist Lev Vygotsky (1896-1934). ${ }^{6}$ Piaget developed the theory of the thinking processes of a child from his early studies from 1926 onward (Piaget, 1929; see the literature in Beard, 2007) and these had a significant role in the development of cognitive constructivist learning theories. Vygotsky developed the social constructivist learning theories in his Psychology of Art (1925) and later works.

Bruner was born blind and it may have had an effect on his later career. He himself noted that, during the first two blind years, he had constructed a visual world in his mind (Greenfield, 2016). Hence, he had a strong intuition that perception is not just controlled by senses but also by mind. His early study $A$ Study of Thinking (Bruner et al., 1956), played a pivotal role in the cognitive revolution that is now called the cognitive sciences. Later, this thinking manifested as cognitive psychology ${ }^{7}$ and as constructivist learning theories or constructivism in education in a wide sense (see Harasim, 2017, p. 62). The Process of Education (Bruner, 1960) brought the cognitive revolution to educational discussion. Bruner proposed the idea of a spiral curriculum where a more complex idea can be thought at a simplified level first and at a more complex level later. Act of Discovery (Bruner, 1961) led to the concept of "discovery learning." Bruner proposed that learners construct their own knowledge by organizing and categorizing information using a coding system. The most effective way to develop a coding system is to discover it rather than being told it by the teacher. In Toward a Theory of Instruction (Bruner, 1966) and Studies in Cognitive Growth (Bruner et al., 1966) he proposed, on the basis of his earlier study (Bruner, 1964), three modes of representation, or as interpreted today, three levels of learning: enactive representation (action-based), iconic representation (image-based), and symbolic representation (language-based). His Actual Minds, Possible Worlds (Bruner, 1986) brought the narratives in the center in creating different worlds in the minds. It is one of the most cited academic books in history (see Greenfield, 2016). ${ }^{8}$ In Acts of Meaning (Bruner, 1990b), Bruner proposed that human behavior is ultimately unintelligible without reference to such mental concepts as intentions and goals, and, as nuanced by Rendall (1991), suggests that the fear of a debilitating relativism results from ignoring the social context within which the acts of meaning take place. The Culture of Education (Bruner, 1996) is a collection of essays, addresses, and

\footnotetext{
${ }^{6}$ Tomic and Kingma (1996) nicely handle the connection of these pioneers.

${ }^{7}$ Bruner calls the cognitive psychology as the "poor cousin" of cognitive sciences (Bruner and Goodnow, 1986).

${ }^{8}$ Google Scholar $\quad$ Citation indexing system (http://scholar.google.com/citations?user=z2mOtmgAAAAJ\&hl=en) shows that this book has been cited more than 17,000 times at the time of finalizing the article (November 18, 2018).
} 
lectures by him about cultural psychology. This book has made some scholars think that Bruner changed his educational thinking in his later years (see discussion in Takaya, 2008).

Bruner was an ultimate optimist for education. He proposed: "We begin with the hypothesis that any subject can be taught effectively in some intellectually honest form to any child at any stage of development" (Bruner, 1960, p. 33). In this matter, he opposed Piaget who thought that there are certain fixed steps for learning dependent on the development of the child. Considering his tremendous influence in the educational practices as well as works and theoretical pondering of scholars in various fields, it is no wonder why Haggbloom et al. (2002) ranked Bruner as one of the most cited ${ }^{9}$ psychologists of the 20th century. His influence reaches much farther than the academic citations psychological journals or psychological textbooks: his ideas have changed the educational thinking and systems in many countries.

\section{Bruner and Cognitive-Linguistic Mnemonic Triggers}

According to Bruner (1983, p. 164), Bruner (1986, p. 114) we use language to communicate, to differentiate between and to order things, and to construct realities. From this point of view, such cognitive-linguistic operations as connecting, differentiating, comparing, and ordering things as well as constructing realities can be thought to be universal ways to save and handle information, stories, and experiences in our brains. The challenge concerning the cognitive-linguistic operations is that, though they are universal, they are language- and syntax specific. Here, the English words are used as examples.

Two simple linguistic triggers for connecting things by using doubles in English are "and" or "or" " $\mathrm{X}$ and $\mathrm{Y}$ "; "X or Y"). We can connect a whole variety of things, for example, "black and white." In this example, two colors are connected (connecting things from the same category, i.e., color), separate colors are connected (connecting things from different categories, i.e., black and white), the order of the colors is connected (connecting things from ordered shades, i.e., from the darkest to the lightest), and metaphorically opposite colors are connected (connecting two extremes). It depends on the situation and the intellectual level of the listeners as to how they understand and interpret the phrase. This expression of doubles is quite similar to another indicator of oral transmission, the expression of three things, triple repetitions, which is a common mnemonic method in narratives (see Section "Bruner and Narrative Mode of Thinking-Metaphors, Similes, Narratives, and Triple Repetitions as Mnemonic Triggers").

Three simple linguistic triggers for comparing and differentiating things in English are "like," "as," "or," and the more complicated "but": ("X is [like] A but Y is [like] B").

\footnotetext{
${ }^{9}$ Haggbloom et al.'s (2002) statistics were based on articles published in psychological journals and introductory psychology textbooks. In these sources, Bruner was cited 3,279 times at the time of their article. However, Bruner is cited much more often in other fields. According to Google Scholar Citation indexing system (http://scholar.google.com/citations?user=z2mOtmgAAAAJ\&hl=en), Bruner has been cited more than 222,000 times (November 18, 2018). His four books Acts of Meaning, Actual Minds Possible worlds, The Process of Education, and Toward a theory of instruction alone are cited more than 61,000 times.
}

In a positive expression, the triggers "like" and "as" are used for a simile ${ }^{10}$ and, in a negative expression, for discrimination. The trigger "but" may differentiate things on two levels: separating two things from each other (nominal discrimination) and separating opposite things from each other (ordinal discrimination). Difference can be stated also by using strict differentiating with triggers "to make a difference," "do not," or "separate from" ("separate X from Y!" or "do not do/be X”). Comparison can be made also by using strict comparison like in "compare" or "the same way": ("compare X with Y" or "in the same way, $\mathrm{X}$ is $\mathrm{Y}^{\prime}$ ).

A simple way to create order in concepts and things is to separate nominal counterparts: "head - toe" or "hands - feet" without specific reference to the order. We can also use nominal order with explicit or implicit order as in "small - big" or "weak strong" or use explicit comparative order such as "smaller bigger [than]" or "weaker - stronger [than]" or superlative order such as "the smallest - the biggest" or "the weakest the strongest" or "A - Z." Yet another way is to use general expressions of (ultimate) extremes such as "all," "always," "never," or "in the end" and "finally."

The last set of cognitive triggers addressed here briefly are the linguistic triggers for constructing knowledge - the narrative and logical triggers are handled in Sections "Bruner and Narrative Mode of Thinking-Metaphors, Similes, Narratives, and Triple Repetitions as Mnemonic Triggers" and "Bruner and LogicalScientific Mode of Thinking-Logical Mnemonic Triggers.” A simple set of linguistic triggers for constructing knowledge are triggers for a light argument and conclusion such as "because of," "for," "so," "thus," "then," "hence," and "therefore" ("X is Y because of B" or "Hence, $\mathrm{X}$ is $\mathrm{Y}$ "). A more complicated way to construct realities is to condition something by the positive trigger "if" ("if $\mathrm{X}$ then Y") or negative "unless" ("unless X, no Y"). We may find many more triggers of this kind. Some profounder logical triggers are handled with the logical-scientific mode in Section "Bruner and Logical-Scientific Mode of Thinking-Logical Mnemonic Triggers."

The relevance of these triggers from the contemporary thinking of memory viewpoint is that these triggers make meaning to the stimulus. As known from the studies of Craik (2017) and Baddeley and Hitch (2017), the more meaningful the analyses of stimuli at hand are, the higher the levels of subsequent retention will be (see Section "Memory and Cognitive Models"). These triggers may also serve in packing the load of information; while using these kinds of connectors, the amount of information that needs to be retrieved may be reduced (see O'Keefe and Nadel, 1998, 388-389).

\section{Bruner and Constructivist Mnemonic Triggers \\ Building on What Is Already Known}

The basic idea of the constructivist learning paradigm is that learning is an active, social process in which a student constructs new ideas or concepts based on his/her current knowledge (Bruner, 1961). One of the basic principles of constructivist

\footnotetext{
${ }^{10}$ Note the difference between metaphor ("X is a fox") and simile (" $\mathrm{X}$ is like a fox").
} 
education is that learning reinforces itself in a spiral way; new things are learned by building on the previous experiences (Bruner, 1960, p. 52). Bruner (1961) proposes that learners construct their own knowledge by organizing and categorizing information using a coding system which should be discovered rather than being told by the teacher.

Two kinds of references can be separated concerning previous experiences: first, reference to something which is already known in a general sense ("As you [already] know...") or reference to generally known common concepts from everyday life ("You have three apples and give one away. How many apples are left?"). Another related mnemonic trigger is the structural repetition $^{11}$ : the teacher organizes the teaching or study material in such a way that repetition enhances the retention. In structural repetition, the same topic, word, concept or idea is repeated in the same or slightly modified way within the same teaching session or material package. Naturally, the teacher can use repetition also-teaching the same topic several times.

The relevance of these triggers from the contemporary thinking of memory viewpoint is that repeating the material is an effective device for remembering (e.g., Tulving, 1967; Baddeley, 1997) though not as effective as the repeated testing of the material studied (Tulving, 1967; Karpicke and Roediger, 2008; Metsämuuronen, 2013; Metsämuuronen and Mattsson, 2013). This may lead to multiple traces to the memory (Lasry et al., 2008); in the modern teaching processes these multiple traces can be enhanced by using feedback via cues during the task process and specifically with the aid of learning technologies (Hattie and Timperley, 2007; Van der Kleij et al., 2015).

\section{Bruner and Narrative Mode of Thinking-Metaphors, Similes, Narratives, and Triple Repetitions as Mnemonic Triggers}

According to Bruner (1986, p. 11), humans have two cognitive modes of thinking: logical-scientific mode and narrative mode (also see Section "Constructivism and Cognitive Psychology in the Contemporary Educational Discourse"). With both these modes, individual experiences are organized and ordered, and given meaning, and problem solving is explained (Bruner, 1986, p. 11; Bruner, 1996, pp. 39, 130). This section focuses on the narrative mode and the next section on the logical-scientific mode.

With narrative thinking, we can explain human behavior and psychic reality-we are willing to create connections between different facts. The narrative mode is focused in the affective and functional structures of teaching. In this mode, such elements as intentions, goals, subjective experiences, and the characteristics of individual are in focus (Bruner, 1986, p. 50; Bruner, 1990b, p. 710). This comes close the rhetorical elements in teachingespecially that of pathos (see Section "Bruner, Aristotelian Rhetoric and Mnemonic Triggers"). Narrative thinking is based on the segments of "not truth," "truth-likeness," and "verisimilitude" (Bruner, 1985, p. 97). Even though a story might

\footnotetext{
${ }^{11}$ It may be worth noting the difference between repetition as a student's activity and (structural) repetition as a teacher's activity. As a student activity, repetition is not a mnemonic device or trigger in the same sense as discussed in this article.
}

not be "true" in a strict sense (like a fable or a parable), it still can be charmingly truthful and credible (Bruner, 1985, p. 113) - the criteria for narrative thinking is whether something is lifelike or has a real-life sense (Bruner, 1986, p. 11). From the cognitive neuroscience viewpoint, using stories and visual images may reduce the workload of memorizing, which facilitate the enhanced recall (O'Keefe and Nadel, 1998, pp. 138-139) as discussed above. Also, they make meaning to the information which enhances the retention (e.g., Craik and Lockhart, 1972; Craik, 2016; Baddeley and Hitch, 2017).

Two powerful constructivist triggers for the narrative mode of thinking are metaphors ${ }^{12}$ ("X is $\mathrm{Y}^{\prime}$ ) and similes ("X is like $\mathrm{Y}^{\prime}$ or " $\mathrm{X}$ is as $\mathrm{Y}$ "). ${ }^{13}$ Bruner (1976), p. 66) assumes that the surprise produced by a metaphor reveals new connections between things; metaphors are used to reorganize and understand human experiences in a new way (Bruner, 1983, p. 205). In narrative thinking, the metaphoric richness and possible contradictions are just as important as the incident to which the metaphor refers (Bruner, 1985, pp. 104-105). A related powerful trigger is the use of the visual image (Bruner, 1984, 1966; Bruner et al., 1966; also Baddeley (1997, p. 133). In Bruner's second level of learning something new (the iconic representation), the knowledge is stored primarily in the form of visual images. Baddeley (1997), p. 133 ff.; see also O'Keefe and Nadel, 1998, pp. 389-390) discusses the visual mnemonics used by ancient rhetoricians; they consider memory a matter of honor and shame. One of the tools for these ancient masters of memorization was the "memory palace" where they stored multiple pieces of information in a visual form and they were able to recall those by wandering in that virtual palace (Yates, 1966).

Another powerful trigger within the narrative thinking is a narrative or story-and especially a logically plotted story (Bruner, 1986, p. 39). With a plot, that is, by a logical connection of events, it is possible to create a temporal synthesis of actions, goals, and intentions in the story. The plot amalgamates the complexity of the events and creates a coherent story. A good story is open to different interpretations because it leaves things slightly vague-different listeners or readers would fill in the gaps with their own experiences and knowledge (Bruner, 1990a, p. 53). When the story is not true in the factual sense, it can

\footnotetext{
${ }^{12}$ Though Bruner is used here as the main source, cognitive linguistic Lakoff's remarkable work on the use of metaphors (Lakoff, 1993; Lakoff and Johnson, 1980) is also worth exploring.

${ }^{13}$ There are some other relevant categories of figurative language than just metaphors and similes (see Glucksberg, 2001, p. 141; Jaszczolt and Turner, 2003, p. 141; Montgomery et al., 2007, pp. 118-121; Harley, 2014, p. 337). In a metaphor, "he/she is a fox" and in simile "he/she is like a fox." In metonymy, "the fox sent an email" while referring to a foxy boss. In synecdoche, "the foxes are coming" when referring to all the different animals in the lot. An allegory or parable is a set of many metaphors: "the fox dam gathers her cubes in the evening" as an image of how a human mother would take care of her child. An apostrophe is used especially in poetry as a rhetorical device when personifying someone or something who is, actually, not there, like "Woe to yee, the foxes!" Idioms are "frozen metaphors" as in "fox's nest" or "lion's den"). Fables are animal stories where the animals represent humans and have human characteristics: "Once, a fox and a bear discussed with each other." Symbols are things that stand for something else more abstract like in "a fox" as a symbol for a wit or sly person. Hyperbole is an overstatement not intended to be taken literally is also figurative language. A pun is as an expression of intended for a humorous effect by exploiting different meaning in words: "The bear wondered why the fox took the stick. Then it hit him."
} 
be a fable, parable or allegory. These are related to metaphors: the non-real stories are actually a set of linked metaphors. The hidden metaphoric nature of the parables can also be explained. Though not always understanding the complete layers of the stories, in any event, all listeners, from children to adults, may get something from the stories or parables depending on their intellectual capacity and experiences.

A third, commonly used mnemonic trigger in narratives, not rising strictly from Bruner's ideas though, is to combine three things together, triple repetitions (e.g., Schultz, 2017, p. 8). Sometimes the triple repetitions can be intensified by adding a gradual increase or decrease in the numbers, values, or some other features as in a famous teaching of Jesus related to the "Matthew effect" where the servants had five, two, and one talent(s).

All in all, the relevance of the narrative triggers from the contemporary thinking of memory viewpoint is that, from the cognitive neuroscience viewpoint, using stories and visual images may reduce the workload of memorizing, which facilitate the enhanced recall (O'Keefe and Nadel, 1998, pp. 138-139) as discussed above. These triggers also make meaning to the stimulus (see Craik and Lockhart, 1972; Baddeley and Hitch, 2017; Craik, 2017). Foremost, using narratives and stories may be strictly connected with the essential procedures of the long-term memory, namely, with our declarative memory, more specifically, with the episodic or narrative memory (see Schacter et al., 2007; Squire, 2009; Eysenck and Keane, 2010; Madore et al., 2017).

\section{Bruner and Logical-Scientific Mode of Thinking-Logical Mnemonic Triggers}

In the logical-scientific mode, we try to explain the physical reality with the tools of logic, mathematics, and sciences, for example (Bruner, 1996, p. 39), and, hence, we construct realities (Bruner, 1983, p. 164; Bruner, 1986, p. 114). The logicalscientific mode is based on the formal and functional structures of thinking; it is based on empirical evidence and logical proofs. Logical-scientific mode comes very close to the concept of logos in Aristotelian rhetoric (see Section "Bruner, Aristotelian Rhetoric and Mnemonic Triggers"). Four types of arguments can easily be differentiated: a light argument, conclusion, reference to the something incontrovertible such as hard-fact data, and logical reasoning. A light argument comes with triggers "because" or "for" ("X is A because of Y"). A light conclusion can be drawn with such triggers as "then," "thus," "hence" or "so" ("Hence, $\mathrm{X}$ is $\mathrm{Y}$ "). These triggers have been handled already in Section "Building on What Is Already Known" under the topic "constructing realities." Reference to hard-fact data is common these days. Referencing to a published journal article or to a set of data with large sample size is as close to a fact as can be: "it has to be true." Logical argument can be presented in several ways. In modern discourse we use deductive, inductive, abductive ${ }^{14}$, and statistical arguments. Another kind of logical mnemonic trigger is

\footnotetext{
${ }^{14}$ Abductive reasoning is used when, based on an interpretation of collected data, a researcher assembles or discovers such combinations of features for which there are no appropriate explanation or rule in the store of knowledge that already exists (e.g., Reichertz, 2007, p. 219).
}

logical order in teaching and the material. If the teaching follows a logical order, it is easier to remember.

The relevance of the logical-scientific triggers from the contemporary thinking of memory viewpoint is, foremost, that they make meaning to the information which enhances the retention (e.g., Craik and Lockhart, 1972; Craik, 2016; Baddeley and Hitch, 2017). The process of giving arguments and logical order or to make conclusions may also relate to the basic mode of the procedural part of the long-term memory (Squire, 2009; Eysenck and Keane, 2010) though its main function is to store something that cannot be put into words (Poldrack and Packard, 2003; Ullman, 2004; Squire, 2009). Namely, it may be possible that the contents of the arguments are stored in the declarative memory while the procedure and logic used in these triggers are stored in the procedural memory. Likewise, these could be connected to the Schacter's ideas (Schacter et al., 2007) of constructive episodic memory as a tool for imagining the future, i.e., building scenarios of possible actions and the causal relations between actions and events.

\section{Bruner, Aristotelian Rhetoric and Mnemonic Triggers}

Bruner and his colleagues (Feldman et al., 1990, p. 220) connect logical thinking and narrative thinking with the classical Aristotelian rhetoric. They remind us that, in Aristotelian rhetoric, the cognitive processes of the mind are divided into two types: the emotional and the rational. Aristotle identifies in his Rhetoric three well-known types of rhetorical "proofs," or modes of persuasion, that is, ways of convincing the listener: ethos, pathos, and logos. Of these, ethos and pathos fall in the emotional or narrative mode discussed already in Section "Bruner and Narrative Mode of Thinking-Metaphors, Similes, Narratives, and Triple Repetitions as Mnemonic Triggers" and logos falls in the rational or logical-scientific mode discussed in Section "Bruner and Logical-Scientific Mode of ThinkingLogical Mnemonic Triggers." Of these three, ethos and pathos are discussed in detail here because the rhetoric viewpoint opens some additional doors to the emotional and narrative thinking of Bruner and to the mnemonic triggers. Here, such rhetoric triggers, which may be related to retention and recalling are focused on.

Ethos refers to the character and credibility of the speakerhow the speaker can make him- or herself believable. Aristotle broadens the original meaning of the word (of moral competence) to encompass expertise and knowledge. Though Aristotle expressly remarks that ethos can be achieved only by what the speaker says, it seems that, in practice, the appeal of the speaker is also based on the (known or assumed) expertise of the speaker. In the modern rhetoric, this kind of ethos could be reached by introducing a speaker in such a way that increases the speaker's competence, for example, "Doctor John Doe" or "specialist Jane Doe." Hence, such actions that are used to increase the value or dignity of the teacher, lecturer, or the teaching material, may be valid triggers for enhancing the retention: it is valuable to listen to this teaching or read this material.

We use pathos to alter an audience's view by appealing to their emotions. Pathos appeals to the emotions by using 
metaphors and stories discussed in Section "Bruner and Narrative Mode of Thinking-Metaphors, Similes, Narratives, and Triple Repetitions as Mnemonic Triggers" as well as in the amplification of matters. Pathos can be conjured by the passion of the speaker or by the number of emotional items included in the teaching. We achieve pathos also by weighting an important matter, introducing peculiar or new ideas to the audience, or by a hyperbole. The stronger is the pathos the more is the effect. Here, the focus is in the strict rhetorical triggers within the Brunerian narrative mode in enhancing the retention. This kind of hook is a rhetorical device to attract the attention of the audience and to make them want to listen to the rest of the speech. These "hooks" can also be a series of intriguing questions or number of other devices to leave the listener wanting more. Aristotle discusses a large variety of feelings such as prejudice, compassion, and anger (Aristotle, 1926, Book 1, 1:4), jealousy (Book 1, 1:5 ), love and hate (Book 1, 1:7; 2:5), joy and sorrow (Book 1, 2:5), shame and shamelessness (Book 2, 6:1-2), courage (Book 1, 5:10), excitement and wonder (Book 1, 11:24, 27) or amusement, relaxation, laughter and ridiculing (Book 1, 11:29), or terror and pity (Book 1, 14:1). Some of the triggers for these emotions are discussed below.

Some practical narrative-rhetorical mnemonic triggers related to pathos are to show ones feelings ("Woe to that person..."); to evoke positive or negative emotions such as empowerment, comfort, and safety or disgust; to use humor, anecdotes, jokes, puns, satire, or hyperbole; to activate the audience with a rhetorical question or by a contact with the audience or direct address to the audience; or it can manifest as playing with words, in aphorisms, and in proverbs. Other ways to raise the pathos are attaching more weight to what is going to be said, attaching more weight to an important matter, or to use intellectually challenging ideas like paradoxes, peculiar ideas, and ideas beyond the common understanding. We can easily find more these kinds of rhetorical triggers related to pathos.

The relevance of the rhetorical ethos and pathos triggers from the contemporary thinking of memory viewpoint is, foremost, that they activate the attention. It is hypothesized that the new associations between items, and between each item and its context, are set up in the focus of attention (Cowan, 1998) and that attention determines what will be encoded (Chun and TurkBrowne, 2007). The more attention is devoted at the time of encoding the more probably we create a memory.

\section{Bruner and Learning by Rhymes, Rhythm, and Music-Phonological Mnemonic Triggers}

For some reason, Bruner was not interested in such elementary mnemonic triggers as rhymes, rhythms, and music in relation with the memory. However, a cognitive psychologist Baddeley (1997), p. 134) notes that the combination of meaning and rhyme is a very powerful device for remembering. Wallace (1994) experimentally showed that text is better recalled when it is heard as a song rather than as speech. A related interesting fact is that aphasic patients, who cannot speak with words because of a severe brain damage, may be able to sing the words, and patients with severe speech problem can increase their word production dramatically by singing (see Skeie et al., 2010, p. 353). These phonological triggers may be cognitive or narrative-we actually do not know exactly why the music and rhythm are effective mnemonic devices. It seems that the storage of rhymes, rhythms, song texts, and other musical elements is somewhere else than where the language-related elements are (see Cohen and Ford, 1995; Kaan and Swaab, 2002; Jeffries et al., 2003).

\section{COGNITIVE, CONSTRUCTIVIST, AND RHETORIC MNEMONIC TRIGGERS-AN OUTLINE}

As a conclusion to Sections "Bruner and Cognitive-Linguistic Mnemonic Triggers," "Bruner and Constructivist Mnemonic Triggers," and "Bruner and Learning by Rhymes, Rhythm, and Music-Phonological Mnemonic Triggers,", the linguisticcognitive, constructive-, and phonological-mnemonic triggers handled are collected in Table 1. The individual triggers in Table 1 are in the order found in the course of the article-they are not in order of importance or weight. The list of triggers is, obviously, not exhaustive though many relevant categories may have been detected. Experts from different domains of science may add remarkably new triggers to the list. The list is operational and theoretical in the sense that we actually do not know how good or essential mnemonic triggers they are. However, they make sense when we think about effective teaching and its effective retention. The list should be taken as a tool to widen the scope about mnemonic tools (see literature in Lubin and Polloway, 2016) and to promote experimental studies. The categorization and the list may form a basis for a theoretical framework for the later studies.

\section{BACK TO THE BEGINNING}

The article started with a practical example of a listening test with two sequences of 31 words. The latter sequence was:

Now, listen carefully because I will ask these concepts in the final examination. The terms of reliability and validity are ultimately important when referring to the trustworthiness of a psychometrical test.

What mnemonic triggers we can find in the sequence in comparison with the theoretical framework in Table 1? At least the following ones:

Now, is a rhetorical-constructivist trigger "Activating the audience."

Listen carefully, is a rhetorical-constructivist trigger "Raising the value or dignity (of the study material)."

Listen carefully, is a rhetorical-constructivist trigger "Attaching more weight to an important matter."

Because, is a logical-scientific constructive trigger "Light argument." 
TABLE 1 | Examples of mnemonic triggers based on Bruner's ideas.

Cognitive-linguistic mnemonic triggers

Strict constructivist mnemonic triggers

Narrative-constructivist mnemonic triggers

Logical-scientific constructivist mnemonic triggers (including logos)
Doubles ("and," "or") ("X and Y"; "X or Y")

Strict comparison ("compare" or "the same way") ("in the same way, $X$ is $Y$ ")

Strict comparative ("better than") ("X is better than Y")

Strict differentiation ("differentiate" or "separate") ("separate $X$ from $Y$ !")

Expression for opposite ("but") ("X is [like] A but $Y$ is [like] B")

Nominal counterparts ("body - cloth," "receive - give")

Extreme counterparts ("good - bad," "sheep - wolf")

Nominal ordering ("big - small")

Comparative ordering ("bigger - smaller")

Superlative ordering ("biggest - smallest")

Extreme values ("all," "always," "never," "in the end" or "finally")

Spiral teaching (enlarging the material in different rounds)

Connecting teaching to something already known ("as you know...")

Connecting teaching to common concepts (e.g., ingredients, traditions)

Structural repetition (repeating word or idea within the teaching)

Repetition of the material (teaching the same matter again)

Repeated testing of the learnt material

Metaphors ("X is $Y$ ")

Simile (" $X$ is like $Y$ ") or ("X is as $Y$ ")

Visual image

Plotted story

Narrative/parable/allegory

Triple repetitions ("three paths to go")

Gradual increase or decrease ("1 - 2-3", "3-2-1")

Light argument ("because" or "for") ("X is $Y$ because of A")

Conclusion ("then," "thus," "hence," "so," "therefore") ("hence, $X$ is $Y$ ")

Condition ("if," "unless") ("if X then Y" or "unless X (no) Y")

Reference to hard-fact data

Logical argument (deductive, inductive, abductive, and statistical arguments)

Logical order (in teaching and in the material)

Rhetoric-constructivist mnemonic triggers (ethos and pathos)

Raising the value or dignity (of the teacher or the study material)

Showing emotions

Evoking positive emotions

Evoking negative emotions

Humor (incl. anecdotes, jokes, puns, satire)

Hyperbole

Activating the audience ("see!," "listen!," "be aware!")

Rhetorical question ("isn't it so?")

Direct address to the audience ("you!")

Collective address to the audience ("you all!")

Playing with words

Aphorisms and proverbs

Attaching more weight to an important matter ("mark my words!"; "remark!")

Attaching more weight to a saying ("surely, I say")

Paradoxical idea

Idea beyond a common sense

Peculiar ideas

Rhymes

Rhythms

Singing 
I will ask these concepts, is a rhetorical-constructivist trigger "Raising the value or dignity of the study material."

Final, is a Cognitive-linguistic trigger "Extreme value,"

Examination, is a Strict constructivist trigger "Connecting matter to something already known,"

Reliability and validity, is a Cognitive-linguistic trigger "Nominal counterparts,"

Reliability and validity, is a Cognitive-linguistic trigger "Doubles,"

Ultimately important, is a Cognitive-linguistic trigger "Extreme value,"

Ultimately important, is a Rhetorical-constructivist trigger "Raising the value or dignity (of the study material),"

Trustworthiness, is a Strict constructivist trigger "connecting matter to something already known,"

The whole sequence, is a Logical-scientific constructive trigger "Logical order (of the study material),"

Hence, it seems that we could find, at least, 13 mnemonic triggers in the short sequence of words for the listener to recall the sequence. Instead of repeating the words-as meaningful as they are-without the meaning, the mnemonic triggers make the learning practically effortless and effective.

\section{DISCUSSION}

All of us have experienced teaching sessions and educational talks of we do not remember anything but the entry and the exit of the speaker-if even that. On the other hand, all of us have experienced lectures, educational sessions, or presentations that were inspiring, empowering, and moving; we came across new ideas, we remember some phrases and stories-we may even be able to repeat some segments word for word from what was said in the speech. Certainly, a good teacher either has been trained in or uses natural rhetorical methods whereas a poorer one stumbles even with simple matters and basic things. A good teaching talk touches our feelings-either positive or negative ones-whereas a dull one consists mainly of semi important matters served in a way that is as dry as dust. A good presentation challenges us intellectually and emotionally whereas a dull and meaningless presentation makes no impact on our mind and feelings. Thus, we can very easily distinguish between these two extremes.

Every teacher wants to see his or her students to learn and prosper. However, luckily in some cases, the teacher's effect on learning is surprisingly low. Based on the meta-analysis of 800 meta-analyses, Hattie found that the teacher effect is around $30 \%$ (Hattie, 2003, 2016; Hattie et al., 2015). That is, the teacher's actions explain (only) 30\% of the variations of the learning outcome in students and the $70 \%$ may be explained by the other factors. In many countries, Hattie's $30 \%$ is an overrating. On the basis of PISA inquiries, Freeman and Viarengo (2014) estimate that the teacher effect is around 20\% in OECD countries which impart common education to all children through the grades 19. In some countries, like Finland, teacher effect is around $10 \%$ (Metsämuuronen, 2017, p. 520); there is practically no differences among the Finnish schools when it comes to the pupils' learning outcomes. ${ }^{15}$ Hence, teachers' actions necessarily do not have much effect in learning if good study material is availabledifferences between the schools may be explained by the selection. Eventually, the learning of a learner happens in the brain of the learner. However, the teachers are willing do their best for the students within those limits.

Though we actually do not even know, comprehensively, what learning is, it has to be something that happens in the human's brain. We do not know yet much of the exact physical location of the higher thinking at the neural level but recent research in locating the physical neural elements in sensing a location give us hint that it may be possible to find other nodes also which could be called the particles of the "mind." When "constructing the world" in a Brunerian sense, we need particles or units for this construction. This article has focused on the tools used by an effective teacher for constructing the worlds by the teaching talk and study material. The specific focus was in the cognitivelinguistic and strict constructivist mnemonic triggers proposed to the enhance retention and retrieval of memory based on the ideas from Bruner. Some phonological triggers were touched upon too though Bruner did not seem to be interested in those.

The memory triggers serve the long-term storage and retrieval in multiple ways. First, we can connect the rhetoric-constructivist triggers to increasing the arousal and attention of the listener, as well as to building the learning situation as an emotionally and cognitively interesting, and memorable, situation supporting the construction of a strong episodic memory representation.

Retention via recollection and familiarity are known to be partly dependent on different memory systems. Recollection is more sensitive than familiarity to response speeding, division of attention, generation, semantic encoding, and requires active construction of the contents to be remembered, while stimulus familiarity is a fast, semiautomatic process (Yonelinas, 2002). Cognitive-linguistic, narrative and phonological triggers help building via categorizing (similarities and differences in the whole or details) representations that support familiaritybased retrieval. Logical-scientific triggers clearly provide food especially for recollection, giving better possibilities to build the learnt content from parts of the information without the need to remember details the learning moment or environment (episodic) or the exact fact or object (familiarity).

The mnemonic triggers found here would serve in two ways. On the one hand, to a teacher they hint what kind of cognitivelinguistic and constructivist elements could be taken into account when preparing a mnemonically rich teaching presentation. On the other hand, the results may give some ideas for an effective textbook writing to enhance understanding, retention, and retrieval of the memory of its users. In contemporary

\footnotetext{
${ }^{15}$ The "teacher effect" or "school effect" is higher in the countries where there are wide differences between the student performance and where the private schools select the highest performing portion of the students. In those cases, the differences between the schools are high, variation within the schools is low, and, hence, the mathematical procedure used (multilevel modeling) detects that the "school" or "teacher" explains the difference highly (see Metsämuuronen, 2017, p. 520). In Nepal, for example, the "school effect" is $68 \%$ (ibid. p. 520). In many cases, the differences between schools can be explained by the selection of the students and in lesser extent by teachers' actions. We have very few large-scale experimental studies that would tell what the teacher's effect in learning really is.
} 
standard classrooms, the teacher does not so much "teach" in the classic sense but merely enables the learning process, helping the learners to learn. We have turned from "being taught by" to "learning from" as Biesta $(2013,2016)$ has described. This will give much more weight to textbooks and other study material. We can relevantly ask how consciously, from the mnemonic viewpoint, the textbooks are prepared. Here, this contribution of the article may be the most valuable: it has brought into light, not only the obvious rhetorical tools used by a talented teacher, but also such unconscious linguistic triggers as may naturally help the students to connect, compare, categorize or order things and to "construct worlds" in the Brunerian spirit. These triggers could be used consciously when preparing the teaching material.

A critical reader would have noticed that the mnemonic triggers suggested in the text have come from the heuristic grounds and they are based on a hypothesis that these kinds

\section{REFERENCES}

Alabdulaziz, M., and Higgins, S. (2017). Understanding technology use and constructivist strategies when addressing Saudi primary students' mathematics difficulties. Int. J. Innov. Res. Sci. Eng. Technol. 6, 1111-1118. doi: 10.15680/ IJIRSET.2017.0601105

Anderson, J. R. (1983). The Architecture of Cognition. Cambridge, MA: Harvard University Press.

Aristotle (1926). "Rhetoric," in Aristotle in 23 22, ed. J. H. Freese, tran. J. H. Freese (Cambridge, MA: Harvard University Press).

Atkinson, R., and Shiffrin, R. (1968). "Human memory. A proposed system and its control processes," in The Psychology of Learning and Motivation, eds K. Spence and J. Spence (Princeton, NJ: Van Nostrand), 89-195.

Baddeley, A. (1997). Human Memory: Theory and Practice. Hove: Psychology Press.

Baddeley, A. (2003). Working memory and language: an overview. J. Commun. Disord. 36, 189-208. doi: 10.1016/S0021-9924(03)00019-4

Baddeley, A. D., and Hitch, G. J. (2017). Is the Levels of Processing effect languagelimited? J. Mem. Lang. 92, 1-13. doi: 10.1016/j.jml.2016.05.001

Bafile, C. (2005). You Must Remember This...": Teaching with Mnemonics". Education World. Professional Development Article. Available at: http://www. educationworld.com/a_curr/profdev/profdev117.shtml [accessed February 17, 2018].

Beard, R. M. (2007). An Outline of Piaget's Developmental Psychology. Original 1969. London: Routledge.

Bhola, S., and Parchoma, G. (2015). "Comparative perspectives on chemistry teaching and learning in higher education," in Proceedings of the IDEAS: Designing Responsive Pedagogy Conference, Calgary, Canada: Werklund School of Education, eds P. Preciado Babb, M. Takeuchi, and J. Lock (Calgary: University of Calgary), 168-177.

Biesta, G. J. J. (2013). Receiving the gift of teaching: from 'learning from' to 'being taught By'. Stud. Philos. Educ. 32, 449-461. doi: 10.1007/s11217-012-9312-9

Biesta, G. J. J. (2016). The Beautiful Risk of Education. Original 2013. New York, NY: Routledge.

Bloom, B. S. (ed.). (1956). Taxonomy of Educational Objectives. Cognitive Domain, Vol. 1. New York, NY: McKay.

Broadbent, D. (1958). Perception and Communication. London: Pergamon. doi: 10.1037/10037-000

Bruner, J. S. (1960). The Process of Education. Cambridge, MA: Harvard University Press.

Bruner, J. S. (1961). The act of discovery. Harv. Educ. Rev. 31, 21-32.

Bruner, J. S. (1964). The course of cognitive growth. Am. Psychol. 19, 1-15. doi: $10.1037 / \mathrm{h} 0044160$

Bruner, J. S. (1966). Toward a Theory of Instruction. Cambridge, MA: Harvard University Press. of triggers could be effective in teaching and learning process. This heuristic hypothesis, however, could be taken as a proposal for more rigorous studies into their real meaning in learning and retention. Mastropieri and Scruggs (1998) and Lubin and Polloway (2016) have provided us with a convincing set of studies of the most obvious mnemonic triggers. The proposed cognitive-linguistic and constructivist triggers urge new sets of experimental studies to confirm how effective they really are in retention and recalling. Intuitively, it is clear that the more sense, connections, and story we see in a piece of teaching or text the more probable it is that we would remember it.

\section{AUTHOR CONTRIBUTIONS}

All authors listed have made a substantial, direct and intellectual contribution to the work, and approved it for publication.

Bruner, J. S. (1976). "Surprise, craft and creativity," in Play - Its Role in Development and Evaluation, eds J. S. Bruner, A. Jully, and K. Sylva (New York, NY: Basic Books).

Bruner, J. S. (1983). In Search of Mind. Essays in Autobiography. New York, NY: Harper \& Row Publishers.

Bruner, J. S. (1984). Notes on the cognitive revolution. oise's centre for applied cognitive science. Interchange 15, 1-8. doi: 10.1007/BF01807938

Bruner, J. S. (1985). "Narrative and paradigmatic modes of thought," in Learning and Teaching the Ways of Knowing, ed. E. Eisner (Chicago, IL: The University of Chicago Press).

Bruner, J. S. (1986). Actual Minds, Possible Worlds. Cambridge, MA: Harvard University Press.

Bruner, J. S. (1990a). Acts of Meaning. Cambridge, MA: Harvard University Press.

Bruner, J. S. (1990b). Culture and human development: a new look. Hum. Dev. 33, 344-355. doi: 10.1159/000276535

Bruner, J. S. (1996). The Culture of Education. London: Harvard University Press. Bruner, J. S., and Goodnow, J. J. (1986). "Preface to the 1986 edition," in A Study of Thinking. With a New Preface by Jerome S. Bruner and Jacqueline J. Goodnow, eds J. S. Bruner, J. J. Goodnow, and G. A. Austin (London: Routledge).

Bruner, J. S., Goodnow, J. J., and Austin, G. A. (1956). A Study of Thinking. Reprinted 1986 with a New Preface, eds J. S. Bruner and J. J. Goodnow (New Brunswick, NJ: Transaction Books).

Bruner, J. S., Oliver, R. R., and Greenfield, P. M. (eds) (1966). Studies in Cognitive Growth. New York, NY: Wiley.

Chomsky, N. (1957). Syntactic Structures. The Hague: Mouton.

Chun, M. M., and Turk-Browne, N. B. (2007). Interactions between attention and memory. Curr. Opin. Neurobiol. 17, 177-184. doi: 10.1016/j.conb.2007.03.005

Cohen, N. S., and Ford, J. (1995). The effect of musical cue on the nonpurposive speech of persons with aphasia. J. Music Ther. 32, 46-57. doi: 10.1093/jmt/ 32.1 .46

Cowan, N. (1988). Evolving conceptions of memory storage, selective attention, and their mutual constraints within the human informationprocessing system. Psychol. Bull. 104, 163-191. doi: 10.1037//0033-2909.104. 2.163

Cowan, N. (1998). Attention and Memory: An Integrated Framework. Oxford: Oxford University Press, doi: 10.1093/acprof:oso/9780195119107.001.0001

Cowan, N. (2017). The many faces of working memory and short-term storage. Psychon. Bull. Rev. 24, 1158-1170. doi: 10.3758/s13423-016-1191-6

Craik, F. I. (2016). "Neuroanatomical correlates of encoding in episodic memory: levels of processing effect," in Memory, Attention, and Aging, ed. I. M. Craik (New York, NY: Routledge), 261-267.

Craik, F. I. (2017). "Neuroanatomical correlates of encoding in episodic memory: levels of processing effect," in Memory, Attention, and Aging (New York, NY: Routledge), 251-257. 
Craik, F. I., and Lockhart, R. S. (1972). Levels of processing: a framework for memory research. J. Verbal Learn. Verbal Behav. 11, 671-684. doi: 10.1016/ S0022-5371(72)80001-X

Duffy, T. M., and Cunningham, D. (1996). "Constructivism: implications for the design and delivery of instruction," in Handbook of Research for Educational Communications and Technology, ed. D. Jonnasen (Mahwah, NJ: Lawrence Erlbaum Associates), 170-198.

Dunleavy, M., and Dede, C. (2014). “Augmented reality teaching and learning," in Handbook of Research of Educational Communications and Technology, eds J. M. Spector, M. D. Merrill, J. Elen, and M. J. Bishop (New York, NY: Springer), 725-745.

Epstein, R. (2016). The Empty Brain. Your Brain does not Process Information, Retrieve Knowledge or Store Memories. Chiba: AEON.

Eysenck, M. W., and Keane, M. T. (2010). Cognitive Psychology: A Student's Handbook, 6th Edn. New York, NY: Psychology Press.

Feldman, C. F., Bruner, J., Renderer, B., and Spitzer, S. (1990). "Narrative comprehension," in Narrative Thought and Narrative Language, eds B. K. Britton and A. D. Pellegrini (Hillsdale, NJ: Lawrence Erlbaum Associates), 1-78.

Freeman, R. B., and Viarengo, M. (2014). School and family effects on educational outcomes across countries. Econ. Policy 29, 395-446. doi: 10.1111/1468-0327. 12033

Geeraerts, D. (1995). "Cognitive linguistics," in Handbook of Pragmatics, eds J. Verschueren, J. O. Östman, and J. Blommaert (Amsterdam: John Benjamins), 111-116.

Glucksberg, S. (2001). Understanding Figurative Language: From Metaphor to Idioms: From Metaphor to Idioms. Oxford: Oxford University Press. doi: 10. 1093/acprof:oso/9780195111095.001.0001

Greenfield, P. M. (2016). Jerome Bruner (1915-2016) Psychologist who shaped ideas about perception, cognition and education. Nature 535, 232-232. doi: $10.1038 / 535232 \mathrm{a}$

Haggbloom, S. J., Warnick, R., Warnick, J. E., Jones, V. K., Yarbrough, G. L., Russell, T. M., et al. (2002). The 100 most eminent psychologists of the 20th century. Rev. Gen. Psychol. 6, 139-152. doi: 10.1037/1089-2680.6.2.139

Harasim, L. (2017). Learning Theory and Online Technologies, 2nd Edn. New York, NY: Routledge. doi: 10.4324/9781315716831

Harley, T. A. (2014). The Psychology of Language: From Data to Theory, 4th Edn. New York, NY: Psychology Press.

Hattie, J. (2003). Teachers Make a Difference. What is the Research Evidence? Presentation at Australian Council for Educational Research Annual Conference on: Building Teacher Quality. Auckland: University of Auckland.

Hattie, J. (2016). Visible Learning. Available at: http://visible-learning.org/hattieranking-influences-effect-sizes-learning-achievement/ [accessed February 17, 2018].

Hattie, J., Masters, D., and Birch, K. (2015). Visible Learning into Action. International Case Studies of Impact. New York, NY: Routledge. doi: 10.4324/ 9781315722603

Hattie, J., and Timperley, H. (2007). The power of feedback. Rev. Educ. Res. 77, 81-112. doi: 10.3102/003465430298487

Haydon, T., Musti-Rao, S., and Alter, P. (2017). Comparing choral responding and a choral responding plus mnemonic device during geography lessons for students with mild to moderate disabilities. Educ. Treat. Child. 40, 77-95. doi: 10.1353 /etc. 2017.0005

Jaszczolt, K. M., and Turner, K. (2003). Meaning through Language Contrast, Vol. 2. Amsterdam: John Benjamins Publishing Company.

Jeffries, K. J., Fritz, J. B., and Braun, A. R. (2003). Words in melody: an H(2)15O PET study of brain activation during singing and speaking. Neuroreport 14 , 749-754. doi: 10.1097/00001756-200304150-00018

Jiang, X., and Perkins, K. (2013). A conceptual paper on the application of the picture word inductive model using Bruner's constructivist view of learning and the cognitive load theory. Interdiscip. J. Teach. Learn. 3, 8-17.

Kaan, E., and Swaab, T. Y. (2002). The brain circuitry of syntactic comprehension. Trends Cogn. Sci. 6, 350-356. doi: 10.1016/S1364-6613(02)01947-2

Kapur, S., Craik, F. I. M., Tulving, E., Wilson, A. A., and Houle S. (1994). Neuroanatomical correlates Of encoding in episodic memory: levels of processing effect. Proc. Natl. Acad. Sci. U.S.A. 91, 2008-2011. doi: 10.1073/pnas. 91.6.2008
Karpicke, J. D., and Roediger, H. L. III (2008). The critical importance of retrieval for learning. Science 319, 966-968. doi: 10.1126/science.1152408

Kolb, D. E. (2014). Experiential Learning: Experience as the Source of Learning and Development, 2nd Edn. Upper Saddle River, NJ: Pearson Education, Inc.

Lakoff, G. (1993). "The contemporary theory of metaphor," in Metaphor and Thought, 2nd Edn, ed. A. Ortony (Cambridge: Cambridge University Press), 202-251.

Lakoff, G., and Johnson, M. (1980). Metaphors we Live by. Chicago, IL: University of Chicago Press.

Lämsä, A.-M., Puèetaite, R., Kujala, J., Heikkinen, A., Riivari, E., and Medeišiene, R. A. (2017). Teaching and learning business ethics in a multicultural group. Int. J. Knowl. Manag. Stud. 8, 83-98. doi: 10.1504/IJKMS.2017.084403

Larsen, D. P. (2018). Planning education for long-term retention: the cognitive science and implementation of retrieval practice. Semin. Neurol. 38, 449-456. doi: 10.1055/s-0038-1666983

Lasry, N., Levy, E., and Tremblay, J. (2008). Making memories, again. Science 320:1720. doi: 10.1126/science.320.5884.1720a

Lubin, J., and Polloway, E. A. (2016). Mnemonic instruction in science and social studies for students with learning problems: a review. Learn. Disabil. 14, 207-224.

Madore, K. P., Thakral, P. P., Beaty, R. E., Addis, D. R., and Schacter, D. L. (2017) Neural mechanisms of episodic retrieval support divergent creative thinking. Cereb. Cortex 17, 1-17. doi: 10.1093/cercor/bhx312

Mastropieri, M. A., and Scruggs, T. E. (1989). Constructing more meaningful relationships: mnemonic instructions for special populations. Educ. Psychol. Rev. 1, 88-111. doi: 10.1007/BF01326638

Mastropieri, M. A., and Scruggs, T. E. (1991). Teaching Students Ways to Remember: Strategies for Learning Mnemonically. Cambridge, MA: Brookline.

Mastropieri, M. A., and Scruggs, T. E. (1998). Enhancing School Success with Mnemonic Strategies. Available at: http://www.ldonline.org/article/5912 doi: 10. $1177 / 105345129803300402$

Mastropieri, M. A., Scruggs, T. E., Bakken, J., and Brigham, E. J. (1992). A complex mnemonic strategy for teaching states and capitals: comparing forward and backward associations. Learn. Disabil. Res. Pract. 7, 96-103.

Metsämuuronen, J. (2010). Why Jesus used Parables? - Jesus' Teachings from the Cognitive and Constructive Psychology Viewpoint. Research Paper at SBL Conference in Atlanta 21.11.2010*.

Metsämuuronen, J. (2013). Effect of repeated testing to the development of Biblical Hebrew language proficiency. J. Educ. Psychol. Dev. 3, 10-24. doi: 10.5539/jedp. v3n 1 p 10

Metsämuuronen, J. (2017). Essentials of Research Methods in Human Sciences. Advanced Analysis, Vol. 3. New Delhi: SAGE Publications, Inc.

Metsämuuronen, J., and Mattsson, M. (2013). Effect of repeated testing to the development of Vocabulary, Nominal Structures, and Verbal morphology. J. Educ. Psychol. Dev. 3, 89-101. doi: 10.5539/jedp.v3n2p89

Miller, G. (1956). The magical number seven, plus or minus two: some limits on our capacity for processing information. Psychol. Rev. 63, 81-97. doi: 10.1037/ h0043158

Miyake, A., and Shah, P. (eds). (1999). Models of Working Memory: Mechanisms of Active Maintenance and Executive Control. New York, NY: Cambridge University Press. doi: 10.1017/CBO9781139174909

Moisala, M. (2017). Brain Activations Related to Attention and Working Memory and Their Association with Technology-Mediated Activities. Doctoral Thesis, University of Helsinki, Helsinki.

Montgomery, M., Durant, A., Fabb, N., Furniss, T., and Mills, S. (2007). Ways of Reading: Advanced Reading Skills for Students of English Literature, 3rd Edn. London: Taylor \& Francis. doi: 10.4324/9780203597118

Nodding, N. (2016). Philosophy of Education, 4th Edn. Boulder, CO: Westview Press.

O'Keefe, J. (1976). Place units in the hippocampus of the freely moving rat. Exp. Neurol. 51, 78-109. doi: 10.1016/0014-4886(76)90055-8

O'Keefe, J., and Dostrovsky, J. (1971). The hippocampus as a spatial map. Preliminary evidence from unit activity in the freely-moving rat. Brain Res. 34, 171-175. doi: 10.1016/0006-8993(71)90358-1

O'Keefe, J., and Nadel, L. (1998). The Hippocampus as Cognitive Map. Oxford: Oxford University Press. 
Phillips, D. (1995). The good, the bad, and the ugly: the many faces of constructivism. Educ. Res. 24, 5-12. doi: 10.3102/0013189X024007005

Phillips, D. C. (1997). Coming to grips with radical social constructivism. Sci. Educ. 6, 85-104. doi: 10.1023/A:1008658528097

Phillips, D. C. (1999). "The two essays of Tapio Puolimatka: a double-barreled response," in Philosophy of Education 1999, ed. R. Curren (Rochester, NY: University of Rochester), 302-306.

Piaget, J. (1929). The Language and Thought of the Child. London: Routledge \& Kegan Paul.

Poldrack, R. A., and Packard, M. G. (2003). Competition among multiple memory systems: converging evidence from animal and human brain studies. Neuropsychologia 41, 245-251. doi: 10.1016/S0028-3932(02)00157-4

Puolimatka, T. (1999). "Constructivism, knowledge, and manipulation," in Philosophy of Education 1999, ed. R. Curren (Rochester, NY: University of Rochester), 294-301.

Puolimatka, T. (2002). Opetuksen Teoria. Konstruktivismista Realismiin. [Theory of Teaching: From Constructivism to Realism]. Helsinki: Tammi.

Puolimatka, T. (2003). Constructivism and critical thinking. Inquiry 22, 5-12. doi: 10.5840/inquiryctnews20032244

Rämä, P., Leminen, A., Koskenoja-Vainikka, S., Leminen, M., Alho, K., and Kujala, T. (2018). Effect of language experience on selective auditory attention: an event-related potential study. Int. J. Psychophysiol. 127, 38-45. doi: 10.1016/ j.ijpsycho.2018.03.007

Reichertz, J. (2007). "Abduction: the logic of discovery of grounded theory," in The Sage Handbook of Grounded Theory, eds A. Bryant and K. Charmaz (London: Sage), 214-228.

Rendall, S. (1991). Acts of meaning (review). Philos. Literature 15, 331-332. doi: 10.1353/phl.1991.0032

Roediger, H. L. III, and Karpicke, J. D. (2006a). Test-enhanced learning: taking memory tests improves long-term retention. Psychol. Sci. 17, 249-255. doi: $10.1111 / j .1467-9280.2006 .01693 . x$

Roediger, H. L. III, and Karpicke, J. D. (2006b). The power of testing memory. basic research and implications for educational practice. Perspect. Psychol. Sci. 1, 181-210. doi: 10.1111/j.1745-6916.2006.00012.x

Rowland, D. C., Roudi, Y., Moser, M. B., and Moser, E. I. (2016). Ten years of grid cells. Annu. Rev. Neurosci. 8, 19-40. doi: 10.1146/annurev-neuro-070815013824

Säljö, R. (2000). Lärande I Praktik. [Teaching in Practice]. Stockholm: Prisma.

Salo, E., Salmela, V., Salmi, J., Numminen, J., and Alho, K. (2017). Brain activity associated with selective attention, divided attention and distraction. Brain Res. 1664, 25-36. doi: 10.1016/j.brainres.2017.03.021

Schacter, D. L., Addis, D. R., and Buckner, R. L. (2007). Remembering the past to imagine the future: the prospective brain. Nat. Rev. Neurosci. 8, 657-661. doi: $10.1038 / \mathrm{nrn} 2213$

Schultz, W. R. (2017). Genetic Codes of Culture?: The Deconstruction of Tradition by Kuhn, Bloom, and Derrida. Routledge Library Editions: Literary Theory. London: Routledge.

Schweder, R. (1991). Thinking Through Cultures. Cambridge, MA: Harvard University Press.

Shore, R. A., and Morris, D. (2016). "The unconference: a constructivist approach to professional development," in Handbook of Research on Teacher Education and Professional Development, eds C. Martin and D. Polly (Hersley, PA: IGI Global), 356-366.

Simola, J., Hyönä, J., and Kuisma, J. (2014). Perception of visual advertising in different media: from attention to distraction, persuasion, preference and memory. Front. Psychol. 5:1208. doi: 10.3389/fpsyg.2014.01208

Skeie, G. O., Einbu, T., and Aarli, J. (2010). "Singing improves word production in patients with aphasia," in Neurobiology of Music, ed. F. C. Rose (London: Imperial College Press), 347-358.
Sökmen, A. J. (1997). "Current trends in teaching second language vocabulary," in Vocabulary: Description, Acquisition and Pedagogy, eds N. Schmitt and M. McCarthy (Cambridge: Cambridge University press), 237-257.

Squire, L. R. (2009). Memory and brain systems: 1969-2009. J. Neurosci. 29, 12711-12716. doi: 10.1523/JNEUROSCI.3575-09.2009

Takaya, K. (2008). Jerome Bruner's theory of education: from early Bruner to later Bruner. Interchange 39, 1-19. doi: 10.1007/s10780-008-9039-2

Taylor, C. (1985). "Cognitive psychology," in Philosophical Papers, ed. D. H. Mellor (Cambridge: Cambridge University Press), 187-212. doi: 10.1017/ CBO9781139173483.009

Taylor, T. J. (1984). Linguistic origins: Bruner and Condillac on learning how to talk. Lang. Commun. 4, 209-224. doi: 10.1016/0271-5309(84)90007-7

Tomic, V., and Kingma, J. (1996). Three theories of cognitive representation and criteria for evaluating training effects. Educ. Pract. Theory 18, 15-35. doi: 10. $7459 /$ ept/18.1.03

Toppino, T. C., and Gerbier, E. (2014). "Chapter four - about practice: repetition, spacing, and abstraction," in Psychology of Learning and Motivation, Vol. 60, ed. B. H. Ross (Burlington, NJ: Academic Press), 113-189. doi: 10.1016/B978-0-12800090-8.00004-4

Tulving, E. (1967). The effects of presentation and recall of material in freerecall learning. J. Verbal Learn. Verbal Behav. 6, 175-184. doi: 10.1016/S00225371(67)80092-6

Tulving, E. (1983). Elements of Episodic Memory. New York, NY: Oxford University Press.

Tulving, E., and Schacter, D. L. (1990). Priming and human memory systems. Science 247, 301-306. doi: 10.1126/science.2296719

Ullman, M. T. (2004). Contributions of memory circuits to language: the declarative/procedural model. Cognition 92, 231-270. doi: 10.1016/j.cognition. 2003.10.008

van Bommel, M., Boshuien, H. P. A., and Kwakman, K. (2015). Appreciation of a constructivist curriculum for learning theoretical knowledge by social work students with different kinds and levels of learning motivation. Int. J. Educ. Res. 71, 65-74. doi: 10.1016/j.ijer.2015.03.002

Van der Kleij, F. M., Feskens, R. C., and Eggen, T. J. (2015). Effects of feedback in a computer-based learning environment on students' learning outcomes: a meta-analysis. Rev. Educ. Res. 85, 475-511. doi: 10.3102/003465431456 4881

Vykotsky, L. S. (1925). The Psychology of Art, trans. Scripta Technica. Cambridge, MA: MIT Press.

Wallace, W. T. (1994). Memory for Music: effect of melody on recall of text. J. Exp. Psychol. Learn. Mem. Cogn. 20, 1471-1485. doi: 10.1037/0278-7393.20. 6.1471

Yates, F. A. (1966). The Art of Memory. Chicago, IL: University of Chicago Press.

Yonelinas, A. P. (2002). The nature of recollection and familiarity: a review of 30 years of research. J. Mem. Lang. 46, 441-517. doi: 10.1006/jmla.2002. 2864

Conflict of Interest Statement: The authors declare that the research was conducted in the absence of any commercial or financial relationships that could be construed as a potential conflict of interest.

Copyright (c) 2018 Metsämuuronen and Räsänen. This is an open-access article distributed under the terms of the Creative Commons Attribution License (CC BY). The use, distribution or reproduction in other forums is permitted, provided the original author(s) and the copyright owner(s) are credited and that the original publication in this journal is cited, in accordance with accepted academic practice. No use, distribution or reproduction is permitted which does not comply with these terms. 